\title{
Relational Cohesion Theory
}

Edward J. Lawler

Cornell University

Encyclopedia of Group Processes \& Intergroup Relations, edited by John M. Levine \& Michael

A. Hogg, 690-691. 
Relational cohesion theory explains how and when people who are exchanging things of value develop stable, cohesive relations. It starts from the idea that people tend to interact or do things with others because they get something they value or want from those others. They give something to the other and receive something in return. This is termed a social exchange. The valued "goods" that are exchanged may be tangible or intangible. Employees exchange their labor for pay, clients exchange money for services, neighbors exchange assistance with each other's yards, coworkers exchange advice and information, roommates exchange respect for each other's belongings, and friends exchange emotional support for each other.

\section{Overview}

Social exchanges are instrumental in the sense that people engage in exchange to get something for themselves, and they may not care what the other gets. Unless people have some sort of commitment to each other, you would expect them to always be searching or "on the lookout” for better exchange partners and to readily leave one relationship for another. Social ties or relations would be like economic markets in this sense, governed and shaped purely by self-interest. Relational cohesion theory asks, Under what conditions will people in social exchange develop a commitment to their relationship?

Commitment is defined as the tendency for people to keep exchanging with the same person or to stay in a relationship despite good or better alternatives. If people have a commitment, they will not be as inclined to search for better alternatives or to choose an alternative over their current relationship if one becomes available. Relational cohesion theory, as the name implies, argues that social cohesion produces a strong form of commitment that 
involves not just staying in the relationship but also giving gifts without strings attached (unilaterally) and partaking in new joint activities or ventures that require or imply trust in the other's goodwill. The theory contends that such commitments form because social exchanges produce emotions (or feelings), and under certain conditions, people associate their individual feelings with their relationship or shared group affiliation. When this occurs, people come to value not only the things they personally get from the exchange but also the relationship or group affiliation in itself.

According to the theory, social cohesion has a structural and a perceptual dimension. Structural cohesion is based on the degree of interdependence, that is, how dependent the people are on each other. Structural cohesion is strong if both people in an exchange are highly dependent on each other for valued rewards (high mutual dependence, or interdependence) and if they are equally rather than unequally dependent on each other. Structural cohesion, however, is an unrealized potential. It makes salient to people that they are involved in a joint task or activity with another and that they cannot accomplish the task alone or without the other.

The fact that they "need" each other for this purpose is important, but it does not necessarily lead to actualized or realized cohesion. Actual or realized cohesion has to be produced and perceived by the people themselves in their interactions with each other. Once cohesion is realized, people tend to become committed and thus are inclined to stay in their relationship, give each other gifts, and trust each other enough to partake in new cooperative ventures that expand or grow their relationship.

Relational cohesion theory indicates that structural cohesion is realized through the emotions and feelings that emerge from repeated social exchanges among the same persons. An emotion is an evaluation state of the human organism that has cognitive, physiological, and 
neurological elements. When you feel an emotion, you "feel it all over,” so emotions refer to generalized states of the human organism. In relational cohesion theory, the emotions of concern are mild states that people often experience in their daily lives, such as feeling good, up, satisfied, bad, down, or dissatisfied. The theory identifies conditions under which such everyday feelings are attributed to relations or groups within which social exchanges occur. This is what causes relational or group commitments to become emotionally based. There are four main points in the theory.

First, social structures bring people together by making them dependent on each other and giving them incentives to interact and exchange. Who exchanges with whom and how often are determined by these interdependencies and associated incentives. People choose to exchange with those from whom they receive the greatest reward or payoff, and at this point, they are oriented only to their own rewards. However, relationships form and evolve when the exchange occurs frequently and repeatedly among the same people. The reasons for this are the next points.

Second, successfully arriving at exchanges with another is an accomplishment that gives people an "emotional buzz.” They feel good about accomplishing the exchange task, whereas unsuccessful efforts to exchange make them feel bad. Repeated exchanges or failures at exchange create patterns of feeling good or bad with another person. Moreover, because social exchange is inherently a joint task, people are likely to believe that their relationship is one reason they are able to repeatedly solve the task (or fail at it). People infer that their emotions, felt individually, are jointly produced by what they share, such as their relationship or group affiliation. 
Third, the theory argues further that positive feelings make more salient the relationship people have to each other and lead them to perceive their relationship as a unifying force in the situation. Thus, repeated exchange produces positive feelings, and these feelings, in turn, foster perceptions of a cohesive relationship, that is, one coming together rather than coming apart. People orient their behavior more to the other and to this relationship than before because the relationship is now a distinct object or force in the situation. They are prepared to do more things on behalf of their relationship with the other, even if it involves costs or sacrifice on their part. Thus, the instrumental, self-interest foundation of their original exchanges evolves into an expressive, symbolic relation with intrinsic value. People continue exchanging with the same others in part to affirm and maintain a valued social relationship.

Fourth, combining the above three points, there is a three-part sequence or process through which a social structure (dependencies) produces commitment: exchange to emotion to cohesion. The effects of social structures are indirect and occur only when this process is produced, that is, when exchange produces positive emotions and these emotions generate perceived cohesion. Commitments to relations will not occur if structures do not generate repeated patterns of exchange among the same people, if those exchanges do not give people an "emotional buzz," or if the resulting emotions do not lead the people to perceive a cohesive relationship with each other.

\section{Related Research}

Many laboratory experiments have been conducted to test the predictions of relational cohesion theory. These experiments bring two or more people together to negotiate agreements 
across a series of episodes of negotiations and vary people's mutual dependence on each other (high vs. low) and also their relative dependence (equal vs. unequal). The evidence strongly supports the idea that equal dependence and more mutual dependence promote commitment behaviors, but only indirectly, through the exchange-to-emotion-to- cohesion process.

Second, the exchange-to-emotion-to-cohesion process has been supported under a variety of different conditions, such as in groups of three working on a joint venture, in networks with four people, and with different types or forms of social exchange. Thus, the idea that frequent exchange produces more positive feelings and more positive feelings produce more perceived cohesion is well founded at this point.

Finally, the theory suggests, more generally, that the effects of group processes on group commitments are strongest when the tasks generate a strong sense of shared responsibility among the people involved in social exchange. Highly joint tasks create a sense of shared responsibility among people doing the task together, and social exchange is one example of a joint task. If people give credit to themselves and not the others for success at a joint task (low sense of shared responsibility), then repeated success at the task should have no effects on cohesion and commitment.

On the other hand, if people give all those involved credit for success (high sense of shared responsibility), the effects of emotions felt on cohesion and commitment should be strong. In this way, the theory of relational cohesion helps explain how and when group processes are likely to produce group cohesion and affective group commitments. Group cohesion and commitment should be especially strong when the structure of the task and the behaviors of people in accomplishing it generate a strong sense of shared responsibility for the results. 